\title{
Reform of College Students' Course Assessment Model Based on Process Control Theory
}

\author{
Qingzhu Qi \\ Tianjin Polytechnic University \\ College of management \\ Tianjin, China \\ 5439112@qq.com
}

\author{
Qing Liu \\ Tianjin Polytechnic University \\ College of management \\ Tianjin, China \\ 809389509@qq.com
}

\begin{abstract}
This paper focuses on the reform of college students' course evaluation model. We apply the system process control theory to shift forward the control point of students' evaluation; change from "feedback control" to "process control", students' learning input can be homogenized. We also strengthen the process management to disperse the pressure of students' final examinations. By means of the proposal of computer examination system design, students' online self-learning and construction of item bank system, we conclude that system process control theory is of practical value for the reform of college students' evaluation model, our conclusions are not only helping to master knowledge for students, but also to avoid the drawbacks of a final examination deciding everything.
\end{abstract}

Keywords-process control; college students; course; evaluation

\section{INTRODUCTION}

Course evaluation ${ }^{[1]}$ refers to the assessment of the progress made in the student's academic course. At present, the Chinese college students' assessment is based on the final examinations. The form of assessment is relatively simple. It cannot objectively, comprehensively and accurately reflect the true level of students, but also has the drawbacks of "a final examination deciding everything". Therefore, through the use of the system control theory, the establishment of new evaluation method of student learning effect, this article applies the idea of process control and beat homogenization in the student's academic evaluation, shifts forward the control point of students' evaluation, which is changing from "feedback control" to "process control" and "feedforward control"; by means of the design of computer examination system, students' online self-learning, the construction of test question bank system, the realistic problems of national conditions are solved such as too many Chinese students, serious cheating and teachers' great workload that makes course process assessment implement ineffectively ${ }^{[2]}$. The paper hopes to provide reference for the improvement of the present evaluation model of college students.

\section{CurRent Situation AND DRAWBACKS of THE PRESENT Course Evaluation Model of Chinese College STUDENTS}

\section{A. Current situation of the present course evaluation model of Chinese college students}

At present, the Chinese college students 'academic evaluation is still in the form of the students' examination papers. The evaluation forms are simple, mainly including written test, improved written test, written test on the machine, other common forms which are put in the assessment results include attendance, training, experiments, discussion, visit, beon-probation, papers, etc., but the assessment forms except the examination is often not taken seriously, and have no standardized assessment criteria, the scientific degree of test proposition is lack of procedural safeguards and scientific testing. So the existing assessment approach is one-sided, do not meet the training objectives. In addition, under the credit system model, the main way to evaluate students' learning is to obtain credits, as long as students have achieved the minimum requirements of the school credits, they would be identified as qualified. Therefore, in a sense, the teaching assessment under the credit system model and the resulting score has become the soul of the current teaching assessment system.

Under the credit system model, college students 'academic evaluation has the following characteristics: (1) The assessment of university students' courses is mainly based on final examinations, attendance and assignments, of which the final exam is the largest; (2) final examinations are mostly in the form of close book, the examination content are mostly about theoretical knowledge, open questions and practical questions appear not much; (3) In order to ensure the final exam pass rate, there is the phenomenon in most schools that teachers designate what's going to be covered on final exams for students; (4) the final examination generally adopt centesimal system, test papers are up to teachers to write their own questions, generally the content taught by teachers in class is mostly the content for the final exam. 


\section{B. Drawbacks of the present course evaluation model of Chinese college students}

- The final examination mode can't fully and accurately reflect students' true level ${ }^{[3]}$. There are "five more, five less" phenomenon in the current course evaluation of students, which are: more close-book examination, less open-book examination; more written examination, less oral examination and other assessment methods; more evaluations are about "a final examination to determine the results", less is about "multiple, many-times evaluation in the whole teaching process to comprehensively determine the result”; more questions with standard answers, less analytic questions with undetermined answers; more theory tests, less exams on practical abilities. Thus, it is often an examination to determine students' efforts on this course result. And because of the influence of random factors, examinations are often not comprehensive, accurate and objective enough to reflect the real level of students.

- The test content of attaching importance to theory instead of practice is not conducive to training students innovative thinking and comprehensive quality ${ }^{[4]}$. In the current assessment system, the assessment is often in the form of final examination, which is dull and unreasonable, a considerable part of students can pass the examination by rote learning, and did not really understand the deep meaning of knowledge, not to mention understanding and application, so it's not conducive to cultivating students' innovative thinking. And many schools pay little attention on the practice assessment of college students, the results of practice courses in the proportion of the entire curriculum performance is small, this will lead to students and teachers to lay less emphasis on class. So it is not conducive to the cultivation of students' comprehensive quality.

- Students have strong speculative awareness ${ }^{[5]}$ so that they prone to cheating ${ }^{[6]}$. In the credit system mode, whether to get credits depends on the final exam results, and the final examination is mainly on theoretical questions, students may pass the exam by rote learning. Therefore, a batch of students will have contempt for the course and students with relatively poor consciousness, self-control may more easily relax on their own requirements, the phenomenon of no reason absenteeism, coming late and leaving early, loose learning discipline may be more serious. Some students even directly cheat, a "high risk, high return investment behavior", instead of bothering to learn what's going to be covered on the exam by rote.

\section{Design of Process-Oriented Course Evaluation of "PRINCIPLES OF MANAGEMENT"}

\section{A. Constructing the evaluation system of students' daily teaching process}

Taking the course of "Principles of Management" as an example, based on the syllabus of "Principles of Management", thinking of process evaluation will be reflected in the content of "Principles of Management", which mainly contains the following:

(1) the basic information of curriculum. It includes course name, course number, total number of class periods, credits, theoretical teaching hours, experimental (practical) teaching hours, etc.

(2) the basic information of lectures. It includes the class, teaching location, teaching time, the teacher, office location, contact information and so on.

(3) the content, requirements and time allocation of courses. It elaborates the main content, class arrangements and other information of each part of the course.

(4) the basic requirements of teaching. It illustrates learning objectives, teaching methods and exercise arrangements.

(5)assessment methods. It determines curriculum assessment methods and proportion.

(6) recommended materials and teaching reference books. It includes the name, author, publisher, publishing time and other information of teaching materials and supplementary materials.

The syllabus focuses on the reform of examination links. Process examination includes 2 exams (machine test) and the assessment of assignments, papers and attendance during the learning process, these two parts account for $70 \%$ of the total score, and the final exam accounts for $30 \%$, as shown in the table. In addition, the final exam, which is open-book, mainly assesses students on comprehensively applying management principles to solve practical problems, as shown in Table 1.

TABLE I. STUDENTS' EXAMINATION RESULTS DISTRIBUTION OF "PRINCIPLRS OF MANAGEMENT"

\begin{tabular}{|c|c|c|c|}
\hline No. & Assessment model & score & proportion \\
\hline 1 & The first Midterm assessment & 100 & $30 \%$ \\
\hline 2 & $\begin{array}{c}\text { The second Midterm } \\
\text { assessment }\end{array}$ & 100 & $30 \%$ \\
\hline 3 & The final exam & 100 & $30 \%$ \\
\hline 4 & Assignments and attendance & 10 & $10 \%$ \\
\hline \multicolumn{2}{|c|}{ The total score } & \multicolumn{2}{|c|}{100} \\
\hline
\end{tabular}

First of all, due to spreading the course assessment throughout the learning process during the whole semester, the process assessment model prevents most students from "being lazy in normal times and cramming for the final exam", improves the student learning atmosphere, and achieves the purpose of promoting study with examination. Secondly, the process assessment is not a qualitative centralized evaluation, so a poor exam performance or being opportunistic may not affect the final results, which is fair and reasonable for each student and a more realistic reflection of students' learning. Thirdly, the knowledge of the phased assessment has relatively strong pertinence; teachers can know about students' mastery 
of knowledge more effectively, reasonably and accurately and find the deficiency in teaching process.

\section{B. Establishing the item bank system of courses for process assessment}

Nowadays, most courses adopt the assessment model of centralized final examinations. As the proportion of final exams is often high, most students pay much more attention to the final exam than usual study. Students learn whatever is going to be covered on the final exam, they study however the final exam will be conducted, which give students a wrong guide for the study thinking, and students think that it's ok as long as they pass the final exam, which entirely is a testoriented mentality. In addition, for the cramming study before the final exam, due to a short time, coupled with too many courses having final exams, some students just learn the concepts and examples on text books, some students find some papers and engage in excessive assignments tactic, some students expect teachers to designate the key knowledge points, and some students simply are going to cheat, etc., so even if the test is passed, it cannot be said that students' mastery of the knowledge do meet the teaching requirements, but the test atmosphere is fueled. To this end, some colleges and universities implement the system of "not allowing teachers to designate the key knowledge points of exams and to set the key exam questions".

In order to solve the above-mentioned problems like teachers designating the key knowledge points of exams, students focusing on cramming or cheating, it's of great significance for the implementation of the separation of teaching and exam in its true sense. For teachers, it will promote to focus on improving the quality of teaching; for students, it helps to correct learning attitude and focus on process learning; for schools, it is conducive to the formation of good test atmosphere, teaching style, study style. Nowadays, colleges and universities pay much attention to the construction of information technology. As an effective means of assisting teaching, information system is playing an increasingly important role. The item bank system is an effective means to implement the separation of teaching and examination. So the item bank of "Principles of management" can be constructed. The item bank is divided into single-choice and multiple-choice questions according to the curriculum sections. Different from the previous development of the item bank, the following basic principles should be grasped in the developing process of the item bank.

- The design of examination questions should pay attention to students' ability of knowledge utilization. Some of the current exams focus on the assessment of students' memory of knowledge, neglecting the assessment of students' comprehensive ability. Although a lot of knowledge points of management courses must be memorized, such as some management principles, laws and regulations, operating procedures, etc., on the other hand, these knowledge points must be combined with practical application, in order to reflect students' mastery of knowledge, so students need to be assessed by multiple modes like practical operation and case analysis, so as to enable students to truly master the knowledge and cultivate their ability. Therefore, in the design process of item bank, in line with the actual needs of courses' own characteristics and training senior management and application talents, test design should strive to assess students' ability, students cannot find the correct answer if they just learn by rote.

- The Design of Question Bank is mainly up to teachers' self-development. The construction of item bank needs long-term planning unified deployment. In order to make the item bank of "Principles of Management" be more in line with teaching requirements, it can be constructed combining with teachers in the course group of "Principles of Management", teaching materials and teaching syllabus. In the beginning stage of the construction of the test question bank system, the main work is combing the knowledge system. The establishment of knowledge system should be relatively stable, not only based on the current use of teaching materials directory, it also should be accurate and complete, and otherwise it will affect the questions quality and follow-up process assessment quality. To this end, the construction of item bank should try to do: the relative stability of the knowledge system; from the motif to start building, trying to develop derivative questions; questions associating with knowledge points accurately and completely; test questions being effective and reasonable.

- The content of item bank should be adjusted dynamically according to the subject development. Management science has developed rapidly in recent years, the knowledge system is updated quickly, therefore, the examination questions database should be regularly maintained and updated by designated teachers from relevant sections, so as to ensure that the content of the test questions database not only maintain the relative stability of knowledge, but also reflect the latest advanced theory of discipline development.

- The item bank should meet the dual needs of students' self-study and online examination. Question bank building is for the process examination services. On the one hand, the number of questions, the quality of test questions, test questions difficulty, examination content are to be required to meet the need of test paper composition and problem-setting; on the other hand, they also should meet the need of students' daily learning, testing and question-answering. Therefore, the answers to all questions should be annotated to facilitate students in usual tests, if answering wrongly; students can clearly understand the causes of errors, to improve students' mastery of knowledge.

\section{Developing and designing the online software system of students' mock exam}

With the support of information system, it is called item bank system that teachers' existing test questions are input into the information system, then test questions are managed, test papers are composed and students are assessed by the 
information system. The online software system of students' mock exam is based on the cultivation of students' selflearning ability, and it realizes learning objectives by students' independent analysis, exploration, practice, questioning and creation. Students can choose their own learning content and their own learning time according to the guidance of their teachers and their own actual situation. According to their own learning style, students can learn actively, take online model test using multimedia classrooms, laboratories, libraries and even dormitories, keep abreast of their learning situation, get the relevant information feedback, and adjust the learning strategy, to seek the best learning results. At the same time, according to the curriculum schedule, teachers can arrange online exams for students at any time using the examination system, set questions and mark automatically by means of system settings, achieving the real process assessment.

Online mock exam system of management courses should mainly include the following functions:

(1) Online learning for students. Students log into "online model test system", then input the course name, degree of difficulty, title and course password etc. After the legitimacy checking of the system, students start to answer questions. After the completion of the examination papers, the system will judge students' answering, and feedback standard answers and the analysis of knowledge points.

(2) Online examination for teachers. Teachers can construct item bank with the system, that is chapter management, topic management etc. If you need to focus on examination, the system also has the function of examinee management, test management, grade query and test paper archiving etc.

(3) Question bank maintenance and construction. Instructors can build the test question bank system of the course according to the teaching situation, and can easily carry out the adding, modifying and deleting of questions.

\section{CONCLUSION}

The paper puts forward a new assessment method of undergraduate education, and introduces the idea of process control into the evaluation of students' learning. It can strengthen the evaluation of students' daily learning process and should proceed from the following aspects.

First of all, multi-disciplinary, multi-angle, scientific and comprehensive evaluation methods of students' learning effect should be established, strengthening daily assessment, comprehensively reflecting student learning attitude and learning effect. From the perspective of the time, students' academic evaluation based on process control distributes the assessment throughout each course, each assignment, every question and every test. From the perspective of evaluation category, it includes assessment in normal times and assessment at the end of course. On the one hand it should improve the proportion of students' performance in normal times; on the other hand it should increase the assessment of students' learning at ordinary times.
Secondly, the use of information technology should be taken notice of. The test question bank system is an effective means to implement the separation of teaching and examinations. To this end, setting up a question bank system, which can replace part of the closed book examination using online test and strengthen the process assessment of students. As a traditional examination method, the closed book examination is necessary in the assessment of certain subject knowledge. The evaluation of basic theory, basic knowledge and basic skills can be carried out in stages of students' learning through 2-4 tests on machine, in order to improve the proportion of students' knowledge-accepting students in teaching process, and strengthen usual learning, so that students can firmly grasp the knowledge.

Thirdly, new teaching process documents should be designed; the teaching process management should be standardized. The current standard of teaching assessment and management in Chinese colleges and universities is low. A unified design of the new teaching process documents should be advocated, and then the normalization of the teaching links of all classes should be improved. The teaching process management should be standardized by the teaching documents and system construction of teaching syllabus, teachers' qualifications and assessment methods. The content of the new syllabus is more rich, including the information of teachers (office hours, class times and places), the specific teaching objectives, text books and other teaching aids, main tasks of courses, basic content learning, classroom form, tasks assigning, scoring and detailed course plans. Students are informed of the program schedule at the beginning of the course, so that the course content, testing and examination time are clear at a glance.

\section{ACKNOWLEDGMENT}

This paper is sponsored by "13th Five-Year" Plan of Science Education of Tianjin, the project name is the construction of process assessment model of college students' course-learning based on intellectual technology (No. HE1002).

\section{REFERENCES}

[1] Willingham W. W., On the Evaluation of Academic Progress, vol. 57, Journal of Educational Research, 2014, pp. 317-373.

[2] Royal P D, Ross T, Afshar M, Does Role Playing Improve Students' Course Performance or Self-Assessment of their Interpersonal Skills? vol. 29, Journal of Health Administration Education, 2012, pp. 229-244.

[3] MEI Ying-jun, Reform of Assessment of College Major Courses, vol.31, Journal of Ningbo University, 2009, pp. 26-27.In Chinese.

[4] ZHOU Xin hua, Nanjing Vocational Education Adult Teaching Research Offi. An Analysis of Vocational Students' Academic Evaluation Model, vol.285, Jiangsu Education Research, 2015, pp. 6567.In Chinese.

[5] Zumbach J, Funke J,Influences of Mood on Academic Course Evaluations, vol.19, Practical Assessment Research \& Evaluation, 2009, pp. 12-12.

[6] Cheng Y R, University G N. Research on Methodology of Improving College Students' Question-Consciousness, vol.16, Journal of Hunan Mass Media Vocational Technical College, 2016, pp.98-100.In Chinese. 